\title{
From "Perpetual Contact" to Contextualized Mobility: Mobile Phones for Social Relations in Chinese Society
}

Yuan, E. J. (2012). From "perpetual contact" to contextualized mobility: The mobile phone for social relationships in Chinese society. Journal of International and Intercultural Communication, 5(3), 208-225. 
This study charts culturally-shaped mobile communication in Chinese society. It finds that Chinese mobile users maintain an open network of contacts comprising not only private relations but work relations and peripheral social ties. Mobile phones are used to define and negotiate in-group membership, maintain social cohesion through mediated rituals, observe relational hierarchies, and preserve social harmony through the use of mobile etiquette defined along spatial, temporal and contextual dimensions. To the extent that mobile phones play into the particularistic, indirect and high-context patterns of Chinese social interaction and relation-oriented cultural norms, the Western mode of "perpetual contact” amongst private relations gives way to a contextualized mobility of diffuse personal ties.

Keywords: Mobile Phone; Perpetual Contact; Contextualized Mobility; Apparatgeist; Chinese Society 
Popular and academic discourse on the mobile phone teems with theses about a technology that is simultaneously "personal" and "social". The mobile phone is personal in that it is often worn on the body (Campbell, 2008a) with personalized fashions and styles (Fortunati, 2002) and is therefore an extension of the self (Gant \& Kiesler, 2001). More importantly, it puts communicative power into the hands of the individual (Geser, 2006). At the same time it is a communication tool for social purposes: People use it to facilitate group affiliation and identity (Ling, 2004), augment political collective action (Castells, Fernandez-Ardevol, Qiu, \& Sey, 2007; Rheingold, 2002), and keep close contact with their family and friends (Campbell \& Park, 2008; Katz \& Aakhus, 2002; Katz, 2008; Ling, 2004, 2008).

Yet the mobile phone also accentuates the tension between the personal and the social. Scholars debate its role in simultaneously privatizing public space and extending the public realm into the domestic (e.g. Livingstone, 2005; Taylor, 2005). The dichotomies of "personal" versus "social" and "private" versus "public" have been central to Western social theory (Fairfield, 2005; Weintraub, 1997). These pairs of multifaceted concepts, as well as the normative assumptions attached to them, underlie much of the scholarly discourse on the mobile phone. For instance, researchers often construct their arguments around the divide between "the private worlds of intimacy and the family" and "the public worlds of sociability or the market economy," or between "the inner privacy of the individual self" and "the interaction order of Erving Goffman's relations in public" (Weintraub, 1997, p. 2). On the one hand, the mobile phone has the power to free people from "the institutionalized tyranny of place and time" (Geser, 2006, p. 8) and bestows upon us the "apparatgeist" of "perpetual contact" (Katz \& Aakhus, 
2002, p. 307). On the other hand, scholars argue that sociability via such a personal device is limited because people mainly use it to communicate with a narrow circle of family and self-chosen friends. Therefore the mobile phone, they suggest, is likely to induce an "anti-evolutionary" trend of relationship downscaling from diffuse social networks to an insular life oblivious to the larger social world (Geser, 2006, p. 8; de Gournay, 2002; Ling, 2008).

The great divide between "private" and "public", however, does not apply equally to all cultures (e.g. Campbell, 2008b; Garcelon, 1997). Chinese society, where indigenous cultural traditions as well as modern social developments prescribe a significantly different social order, exhibits distinctive social relationship dynamics that do not clearly demarcate between "private / public" and "work / life" boundaries. Consequently, mobile sociability in Chinese society is defined not so much by an extension of the self and perpetual contact with the private realm of family and friends as by contextualized interaction with diffuse personal ties on open mobile networks.

China is among the world's largest and fastest growing mobile communication markets and in metropolitan areas, there are more mobile phones than people (Chinese Ministry of Information Industry, CMII hereafter, 2010). This study aims to identify some characteristics of Chinese mobile communication and discusses how social context and communicative norms of Chinese society affect these practices. It sits alongside the Intercultural New Media Forum which recently featured in this Journal (Shuter, 2011). While the Forum articles largely focused on the ways intercultural communication was enabled and performed through new media, here the ultimate goal is to understand social processes through the study of Chinese mobile communication (Katz \& Aakhus, 2002). 
In this context, Chinese social psychology may provide a richer account of mobile sociality.

This paper first presents a detailed discussion of distinctive social relationship and communication patterns in China against the backdrop of its cultural traditions and current development. It then provides a brief introduction to the current state of mobile phone diffusion and use in the country. Finally, after a short description of the qualitative interview method, some key findings from the study are presented and discussed with reference to how cultural and other socio-political factors influence the uses of mobile phones in Chinese society and what this implies.

\section{Chinese Social Relations and Communication Practices}

Communication is fundamentally a social process. As such, it is subject to the influence of the cultural traditions and social context in which it occurs. Chinese society, heavily influenced by Confucian philosophy, has long considered harmonious human relations to be not only the precondition of social integration and stability but also central to the formation of individual identity (Chang, 2001; Chen, 2008; Chinese Cultural Connection, 1987; Hwang, 1987; Yum, 1988). Consequently, the Chinese perspective on communication has some distinctive characteristics. It features webs of instrumental personal ties, a particularistic style and relational hierarchies in a receiver-oriented, highcontext framework (Chang, 2001; Yum, 1988).

While people in Western societies generally strive to protect their private life from the domains of public institutions and market transactions by separating personal relationships from instrumental business or work relationships (Fairfield, 2005; Garcelon, 
1997; Weintraub, 1997), there is a tendency to conflate personal and work relationships in Chinese society. Goodwin (1999) has shown that in East Asian societies the workplace is often seen as analogous to the family environment, with a strong emphasis on maintaining harmonious work relationships. Moreover, people are inclined to take a more personal and human approach to business and work relationships because commodity exchanges carried out on a calculated and contractual basis conflict with Confucian principles (Yum, 1988; Zhu, Nel, \& Bhat, 2006). Therefore, Chinese relationships often diffuse through private / public boundaries with both emotional and utilitarian components (Gold, Guthrie, \& Wank, 2002; Hwang, 1987). Spending "private” time cultivating long-term friendships among work colleagues is often an important part of the work experience (Goodwin, 1999).

Moreover, people in Chinese society tend to develop particularistic interactive rules and patterns according to the relational contexts in which the interactions occur (Chang, 2001; King, 1991; Yum, 1988). Social harmony is achieved by evaluating and managing personal relationships in accordance with principles of relational hierarchy based on rules, status and authorities (Chinese Cultural Connection, 1987). This particularism in social relationship contrasts with universalistic principles in individualistic societies which emphasize that people's social orientations are governed by common standards independent of the particular relation between them (Parsons, 1951).

Chinese cultural norms prescribe exquisite interpersonal rules, such as renqing (emotional obligation to help) and mianzi (face), that serve to maintain mutual dependence among people enmeshed in their social networks (Gold, et al., 2002; Hwang, 1987). On the other hand, in interactions with those outside their social networks people 
apply strict rational equity rules (Hwang, 1987). In essence, Chinese social relations mark a clear distinction between in-group and out-group members, which differs from the divide between the self and the social or the private and the public in Western societies. It is imperative for an outsider to seek the help of an insider, who serves as an intermediary, in order to establish in-group membership (Yum, 1988).

Furthermore, Chinese normally engage in indirect modes of communication in which messages are often implicit, with meaning to be inferred from contextual cues or internalized in interlocutors themselves (Chang, 2001). Hall (1976) succinctly summarized this characteristic of Chinese communication as a high-context communication style and distinguished it from a low-context style:

High context transactions feature pre-programmed information that is in the receiver and in the setting, with only minimal information in the transmitted message. Low context transactions are the reverse. Most of the information must be in the transmitted message in order to make up for what is missing in the context (p. 101).

Consequently, infinite interpretation and "anticipatory communication" are common practices in Chinese communication (Yum, 1988, p. 385).

Both cultural relationship dynamics and communicative patterns are subject to social historical development. Scholars have argued that legacies of shortage economics with weak legal infrastructures in China's communist regimes contributed to the prevalence of particularistic social relations and personal networking in economic transactions (Gold, et al., 2002; Garcelon, 1997). More importantly, Chinese social values are being subjected to significant transformation as China goes through a rapid 
modernization process (Hwang, 1987; Gold, et al., 2002; Garcelon, 1997). Yan (2010) has observed the "individualization" of Chinese society. On the one hand, the increased social and geographical mobility has "disembedded" individuals from traditional social categories (such as community and family) and social institutions (such as danwei and gongshe). As a result, the self-reliant individual has become increasingly important in the structural arrangement of individual-group-society relationships. On the other hand, individuals must continue to rely heavily on personal networks for resource sharing due to the deficient social welfare system and the decline of social trust in China, a country in rapid transition to a market economy.

Media researchers (e.g. Benkler, 2006; Wellman, 2001) have recently taken a network approach to new communication technologies, treating mobile phone users as active nodes in their own mobile communication networks (Choi, 2007). This new network sociality is often characterized as voluntary, egalitarian and transient. How do the technological mobile network and traditional social network mutually constitute each other in the current Chinese cultural context? How does the resultant new sociality accommodate the changing predispositions of Chinese users embedded in personal networks with traditional attributes of mutual dependence? These important questions remain unanswered.

\section{Mobile Phones in China}

The number of mobile phone users in China rose to 766 million, about $56.3 \%$ of its 1.3 billion population, in early 2010, (CMII, 2010). Mobile phone penetration rates are much higher in metropolitan areas: there are about 107.7 mobile phones in use per 100 people 
in Beijing, 111.9 in Shanghai (CMII, 2010). The mobile phone is more prevalent as a means of communication for people compared with other ICTs. There are about 314 million landline phones and 384 million Internet users in China, both less than $30 \%$ of the population (CMII, 2010). By comparison, in the U. S., $85 \%$ adults owned a mobile phone and 74\% used the Internet in 2009 (Pew Research Center, 2009).

China is also world's largest handset manufacturer. Market competition keeps the price within reach of almost everyone who cares to own a mobile phone. Chinese mobile users either subscribe to regular services or purchase prepaid phone cards provided by China's three major mobile phone companies. Unlike U.S. mobile phone services, those in China typically charge by usage volume instead of a flat monthly fee. Therefore, Chinese users are less likely than their U. S. counterparts to concentrate their calling during night hours when the calls are free. Furthermore, handsets are not locked to the service provider and are sold separately by mobile phone manufacturers in China. Hence, Chinese mobile phone users enjoy more freedom to choose or switch their handsets than American users.

Short Message Service (SMS), or text messaging, is immensely popular in China. More than 784 billion messages were sent in 2009, with an average user sending about 90 messages per month (CMII, 2010). Message volumes are especially high during holidays: Over the Chinese New Year holiday in 2010, for example, more than 18 billion messages were sent, 24 per user (Wang, 2010).

Scholarship on mobile communication in Asia - the region that has seen the fastest growth of the mobile media_-abounds. While much attention focuses on the diffusion / adoption of the mobile technologies, as well as the industry and market 
dynamics in the region, there has also been a growing body of literature focusing on the use and social implications of the mobile phone in the context of the region's diverse cultural backgrounds. Ishii (2006) found that young Japanese who tended to avoid direct communication relied on mobile mail to maintain existing bonds rather than to create new ones. Wei and Lo (2006) showed that in Taiwan, the mobile phone served to strengthen users' family bonds, expand their psychological neighborhoods, and facilitate symbolic proximity to the people they call. Choi (2007) investigated the role of the omnipresent mobile phone for perpetual identity management in East Asia. She argued that in interdependent cultures, the self is increasingly constructed and sustained by its social environment via network technologies. Kim, Kim, Park and Rice (2007) established that mobile phones tended to be used to reinforce strong social ties in Korea. Shuter and Chattopadhyay (2010) demonstrated that the U. S. and India have developed culturally different "textiquettes"- the architecture of interpersonal norms guiding text messaging. Diverse in their methodological approaches, these studies reveal that the forms and effects of mobile communication and the cultural environment in which they are embedded are mutually influential.

However, research on mobile phone use for social relations in China is notably limited. Exceptions include mobile phone use by low-income communities such as migrant workers. According to Qiu (2009), inexpensive mobile phone services provide a critical seedbed for the emergence of a new working class of "network labor" crucial to China's economic boom. Likewise, Law and Peng (2008) showed how the mobile phone enables socially unprivileged peasant workers to expand their social networks and exchange job information, which empowers them in struggles against critical working 
and life situations.

Current data about mobile phone usage in Mainland China is also hard to come by. A 2006 survey of a convenient sample of 487 Beijing inhabitants showed that they used their phones more for social communication and study/work purposes than for entertainment. Moreover, $81 \%$ of the respondents declared that the mobile phone increased their social connectivity and the number of contacts in their social networks (Fortunati, Manganelli, Law, \& Yang, 2008). This contrasts with findings in the West where the main purpose of mobile phone calls is to maintain continuing connections with family and friends (e.g. Wajcman, Bittman, \& Brown, 2008).

\section{Method}

This study is a preliminary investigation of how social network and patterns of communication have developed in the face of mobile communication in China. It focuses on urban areas where the mobile phone has reached highest penetration rates. The use and social implications of the mobile phone in more developed urban areas necessarily differ from those in lower-class rural areas due to China's considerable urban-rural development gap. Given the rapid urbanization of China, however, observations in urban areas may provide insights for understanding the social implications of mobile technology for the future development of the society.

In-depth interviews were carried out in private settings in December, 2009. Since Chinese do not usually engage in conversation with strangers or outsiders (Chang, 2001), interviewees were first acquired through personal contacts and mutual acquaintances. A snowball sampling technique was then used to expand the sample to a total of 20 
interviewees. All interviewees lived in metropolitan areas. Eleven were male, seven were between 24-35 years of age, nine between 36-45, and the remaining four were above 45 . The study deliberately excluded teenagers and undergraduate college students, a demographic group with rich experience of mobile telephony, but with social relationship structures and practices drastically different from those of adults (Wang \& Wellman, 2010). All interviewees had at least a high school education. Most held various positions with commercial firms. The exceptions were a high school teacher, a college professor, a doctor, a small business owner, a housewife, and a retiree. The rich and varied social experiences of this sample rendered it ideal for the purpose of this research.

The interviews, conducted in Chinese, ranged from approximately 45 to 90 minutes. The interviewees' statements quoted in the Findings section of this study were translated into English from the original interview transcripts by the author. The interviews used a semi-structured protocol that consisted of three open and nondirective research questions concerning mobile phone use and social networks: a) How, in general, do people use the mobile phone for social relationship in China's urban areas? b) How have cultural values affected the use of the mobile phone for social relationship? c) How has mobile communication affected the traditional social network dynamics? Specific questions followed each of these general questions to generate a more detailed description of mobile social network communication norms. Such questions included who they often call (family, friends, or co-workers); when and where; the use of caller ID and etiquettes.

The interview structure allowed the researcher to focus on important topics while ensuring that the interviewees had the opportunity to fully describe their experiences. The 
researcher employed relevant probes in the conversation to let the interviewees elaborate on their accounts in order to acquire a more comprehensive understanding of their responses. At the conclusion of the interview, a clearinghouse probe was used to ensure that no important information was omitted.

The study followed the constant comparison approach for qualitative data analysis (Lincoln \& Guba, 1985). The iterative process involved the following steps: a) identify important recurring themes to create categories in a preliminary analysis of the data, b) elaborate on dimensions within the categories as well as provide more examples for each category in the subsequent more rigorous rounds of data examination, c) explain how the categories account for the emerging themes and modify and reformulate categories as the data dictates, d) and finally, identify patterns and relationships to develop the final themes. This recursive process was an effective way for the researcher to classify, categorize, and synthesize the themes emerging from the data.

\section{Findings}

Three themes emerged from the interviews: 1) the role of the mobile phone in helping Chinese users register, organize, and negotiate their social networks; 2) mobility as mobile etiquette for relational hierarchies; and 3) mobility as a strategy for social harmony. The remainder of this section elaborates on these themes, based on the informants' comments.

\section{Mobile Social Network in Chinese Society}


Chinese users use their mobile phones to register and maintain their social networks, which are made up of diverse social ties of one or more relational dimensions. All interviewees were quick to acknowledge that their mobile phone contact lists contained almost all of their social connections. These mobile connections included not only family members and friends but also a large number of contacts from work and daily encounters. For instance, Ms. Jiang, a high school teacher, kept in touch with all her students and their parents as well as some of her colleagues via her mobile phone. Mr. ZL, a university professor, communicated regularly with his graduate students and colleagues using his mobile phone. Ms. Hong, a small business owner, managed a complex mobile network consisting of her clients and employees, as well as the officials of local government agencies that administer her business. Mr. Zhang, a VP of a large adverting agency, had more than 2,000 contacts stored in his phone. Mr. GZ, a retired philatelist, preferred his mobile phone to his home phone for communicating with both his long-time friends and new acquaintances from the local antique market.

Ms. Jiang: These days, kids in school all have mobile phones. It is the best way to keep in touch with them. They'd text me about homework and stuff. I also communicate with the students' parents this way. For instance, if a student had an unexcused absence, I'd send an SMS to his/her parent(s) to see what's going on. Not to the student. He might lie... The parents would text back telling me the kid was sick and they forgot to let me know... They'd also call me or text me if they're not sure about something about their kids... It's common. Many teachers in my school do that too. Some schools use text messages as a formal channel to 
communicate with the students and parents regularly. Sending out announcements and things like that.

Mr. Zhang: My company doesn't require employees to print the mobile phone numbers on business cards. But all my business acquaintances, advertisers and the media alike, exchange mobile phone numbers rather than office numbers. I can't afford to be an exception...I have more than 2,000 contacts in my address book, which I simply can't do without... Only a very small portion of these contacts are family members...I often relay fun group SMSs to people. It's good way to keep in touch.

The above accounts illustrate themes consistent across the study sample indicating that mobile communication is widespread among both professional relations and casual acquaintances in China. People tend to opt for the convenience of the mobile phone over the formality of the office landline phone. Although the personalization of work relations in Chinese society certainly did not start with the mobile phone, the increasingly prevalent technology has done much to encourage and promote spontaneity and a personal style in such communications.

While the various social relationships the user is embedded in have collapsed into the mobile network, a large reservoir of superficial contacts is not necessarily equally integrated into the user's social network or in-group. Social relations are still being defined by meaningful interactions guided by cultural norms. The mobile phone has inevitably become a platform for playing out these social dynamics. For instance, the 
following example illustrates how the mobile phone was used for negotiating in-group membership:

Mr. Ma (a doctor): ...I sometimes give my mobile number to patients. Sometimes I get a call from someone who says to me: “Ah, Dr. Ma, I was one of your former patients. You gave me your mobile phone number last time. So could you kindly do me another favor?..."

In this case, the patient caller used Mr. Ma's personal mobile phone number as evidence that an ongoing relation existed between the two parties. Both Mr. Ma and the caller were aware that once the latter managed to confirm his in-group membership, cultural norms dictated that he was more likely to get the help from Mr. Ma.

At other times, the mobile phone becomes an intermediary in relationship building. In the following examples, the mobile phone facilitated the first step in establishing a new relationship:

Mr. Yuan: ... Just last week, my friend gave me the mobile phone number of one of his friends, who is in charge of the admissions office of the MBA program I am applying to ... The mobile phone number is definitely much more helpful than an office number...She would be less likely to say no to my request.

Mr. Zhang: A convenient way for me to introduce someone to someone else is to pass his/her mobile number to the other party. 
The phone numbers were not the only items that got passed on in these situations. A certain level of personal endorsement of the potential relations by the intermediaries was also given. Network social capital was passed on along with the phone calls. However, phone calls alone play only a limited role in constructing strong social ties. Ultimately, the nature of the relationship is decided by the particular context and the subsequent interactions between the two parties involved.

Furthermore, mobile communications serve as mediated rituals for in-group definition and interaction for Chinese mobile users. Ling (2008) defines a ritual as a communal experience in the process of sociation. In China, in-person holiday greetings or visits to family and close friends have traditionally been important rituals. Mobile communication plays perfectly into these long-established traditions and makes it possible to expand the scope of interaction to a much larger group of connections through people's mobile phone contact lists. Each year, Chinese mobile users send tens of billions of SMSs during holidays and important personal occasions (CMII, 2010; Wang, 2010). Students send greetings to their teachers, patients to doctors, businessmen to clients, and employees to bosses. People are able to establish "mutually recognized focus and mood" among themselves through such social rituals (Ling, 2008, p. 9). And some are socially shrewd enough to take advantage it:

Ms. ZZ: It is actually a good time for me to update my address book. People sign their messages. So I'd find out if someone, whom I haven't heard from for a long time, has a new number. 
In summary, the mobile phone helps Chinese users register, maintain and organize large mobile networks of both strong and weak ties from various aspects of their life. However, peripheral connections on the contact list do not always turn into strong ingroup relationships. In-group membership negotiation and interaction are guided by relation-oriented cultural norms. Mobile communication plays into these dynamics and helps reinforce some traditional social practices and modify others.

In comparison to the West, the interviews reveal a much higher degree of integration of the private and public associated with the mainstreaming of mobile communication in Chinese society. This may be because the divide between private and public life is less rigid in the socio-psychology of Chinese users than in Western cultures (Gold et al 2002; Kim, 2002; Kipnis, 2002). While in the U.S. and Europe, the normative use of the mobile phone is prescribed along the clearly demarcated boundary between the private and public, Chinese users are much less resistant to the increased blurring of the two spheres. This reflects one of the key features of Chinese communication. These observations of Chinese mobile phone uses present interesting contrasts, although not direct contradictions, to the popular understanding of mobile telephony as socially limiting experiences mainly among narrow and tightly-knit groups of family and friends in the Western cultural sphere (e.g. Geser, 2004, 2006; Katz \& Aakhus, 2002; Ling, 2004, 2008, Wajcman, et al., 2008).

\section{Mobility as Mobile Etiquette for Relational Hierarchies}

Scholarly discourse on the mobility enabled by mobile technologies often focuses on its 
spatial and temporal dimensions. Much research celebrates the power of such technologies to surmount geographical barriers and temporal rigidity in human communication. Researchers maintain that mobile technologies have made communicative practices independent of geographical proximity (Katz, 2008) or even “abstracted from physical space” into a virtual world (Jones, 1998, p. 15; Taylor, 2005). The mobile phone has also allowed us to overcome the hegemony of the mechanical clock's linear temporality, and micro-coordinate our daily activities (Ling, 2004). It ffacilitates an increased level of poly — rather than mono — chronicity in our daily activities (Fortunati, 2002). Moreover, mobile communication instills the spirit of perpetual contact (Katz \& Aakhus, 2002). In summary, mobile communication is associated with a mobile lifestyle in which individuals have a great deal of temporal and spatial autonomy: they can maintain contact and accessibility while being free to relocate (Katz \& Aakhus, 2002).

However, discussion of mobility is not complete without considering a third dimension, contextuality. This refers to common situational and relational elements (Kakihara \& Sorensen, 2002). Mediated interaction usually has a more limited set of social and contextual cues than face-to-face communication does. While some consider the former inferior to the latter for that reason, many embrace it as a potentially democratizing force that allows people to transcend differences in their backgrounds when communicating (Ling, 2008).

Chinese culture has long emphasized the importance of contextuality in forming appropriate social relationships. "Appropriate" behaviors often mean flexibility and adaptability with respect to the situation and the relationship. Chinese strive for the best 
outcome of human interactions by adapting to the contextual elements of a given interaction including time, space, people, and situation (Chen, 2008). Consequently, as a crucial disposition of interaction in Chinese communication, relation-oriented contextuality often subdues pure spatial and temporal concerns.

The interviews showed that Chinese users often develop and observe individualized mobile etiquettes, much like differentiated linguistic codes, with their mobile interlocutors. Elements of such etiquettes include where and when to make or answer a (inter/disruptive) call; how fast one returns a missed call; when one texts instead of calling; and so on. In a receiver-oriented high-context culture, people often formulate such etiquettes by anticipating how the other would want to be treated.

Fairfield (2005) demonstrated that Chinese culture was not unique in having personal relations "spontaneously regulated by tacit yet generally shared understandings of social distance" (p. 17). However, he pointed out that in individualistic cultures, this tacit code emphasizes that the social distance is decided by the will of both persons on an equal basis (Fairfield, 2005). By contrast, social interaction in Chinese society is characterized by hierarchical power dynamics. Hwang (1987) defined power in this context as "the sociomoral suasion, or peer-group pressure, that one may use to change the attitude, motivation, or behavior of another to conform to one's will during the process of social interaction" (p. 947). The party with more social resources is often the one favored in the power structure. Consequently, mobile phone etiquettes usually manifest power dynamics in social interaction in Chinese society. 
Ms. Wang: I usually call my professor during the morning. That's when he's most likely available. I know he takes naps around noon so I would definitely not call him during that time...

Ms. ZZ: I have this ritual with him [her boss]. I would first call his office. If I have to call him on his mobile phone, I'd first ask if he's busy and if it is a good time to talk...

Mr. Liu: If you have a call during a meeting, you could mute the call, step outside to answer it, or simply answer it on the spot after saying "excuse me" as a gesture of courtesy. It depends on your position [in the company].

Mr. Zhang: I call or text people [his subordinates in the company] sometimes at midnight. If they don't answer it, I would think they are being irresponsible - they should know I call because the matter is important.

These examples clearly illustrate social hierarchy in Chinese mobile communication. While the more powerful party usually can afford to be more obtrusive and enjoy higher degrees of privacy, the less powerful party is required to be more discreet and careful in observing etiquette in their communication.

Unlike phone calls, SMS is an asynchronous mode of communication. It is often preferred over calling for situations which require the reception and response to take 
place at more appropriate times (Ling, 2004). Yet SMS still bears out the power relations between communicators.

Mr. Ma: If it involves a difficult matter I would text my boss. So that I have time to carefully word what I have to say to him, and he has enough time to think for a response... It could be a long message with a formal appellation and wording.

Mr. ZZ: My boss called him [a dean of a university, who is well-respected in the industry] about my visit first. Then I texted him to introduce myself and set up the specific appointment. I also texted him on my way there the day I visited... No, I don't think texting him is rude or improper. It's better than calling - he is busy. He wouldn't be interrupted this way.

Rheingold (2002) predicted that mobile technology development would lead to the next "social revolution", reshuffling and undermining existing social hierarchies and power structures. However, as the above examples demonstrate, mobile communication can reinforce the asymmetries of the existing social order. Moreover, they show that spatial and temporal mobility is often constrained by contextual considerations and thus the idea that mobile phones can be used anytime, anywhere needs to be tempered by the reality that people foster social relations in the context of culturally normative expectations (Campbell, 2008a; Fortunati, 2002).

\section{Mobility as Strategies for Social Harmony}


Boase (2008) points out that a social tie consists of a behavioral as well as a cognitive dimension. While the former is gauged by actual patterns of interaction, the latter refers to cognitive relationship clues such as "the belief that a social tie exists, as well as feelings of closeness, memory of past interaction and knowledge about that tie" (p. 493). Existing mobile phone research tends to focus on the effects of mobile communication on the behavioral dimensions of social interaction. It often gauges the strength of a social tie by the frequency or length of calls between the two people. For instance, "hypercoordination" (coordination of social activities through frequent phone calls) often happens among parties with close relations (Ling, 2004, 2008). Chinese users, however, place equal emphasis on the cognitive aspect of mobile communication: through their mobile interactions they send and receive relationship cues such as degrees of sincerity and emotional input. These uses manifest the high-context communication style of Chinese society (Hall, 1976), as the following examples demonstrate:

Ms. ZZ: If you leave your mobile number, it shows you are more sincere in starting the relationship than if you leave your office number ...

Mr. ZL: It's easy for people to change mobile numbers these days. You can get a new number as effortlessly as you buy a pre-paid phone card. If you're a small business owner and you have always used the same mobile number, say, for 10 years, it says about your integrity and honesty. People would trust you wouldn't disappear on them. 
Ms. Pang: I changed to a new number last year because of my boyfriend. He wasn't very happy that I kept in contact with my friends, whom he didn't like...mainly my former boyfriend... I dropped his number (her former boyfriend's) this way. I wanted to show my (current) boyfriend I was sincere. The past is the past.

Nardi (2005) argues that relationship norms affect mediated communication through three dimensions of "communicative readiness": affinity (an openness to interaction), commitment (the level of engagement in ongoing communication), and attention (p. 91). People constantly monitor, negotiate, and manage these three dimensions for various communicative purposes of relationship maintenance. In addition to exchanging content-oriented messages, the mobile phone can be used to cultivate a “connected presence” (Licoppe \& Smoreda, 2005) or "field of connection” (Nardi, 2005), whereby people signal awareness and preferences with specific others, indicate their (un)availability, and manage the social context for communication (Kim et al, 2007).

Although harmonious social relations is the ultimate goal of Chinese communication (Chang, 2001; Chen, 2008), this does not mean that Chinese are hopelessly entangled in networks that impose social connections and interactions. In fact, it is not uncommon for people to consciously avoid connecting themselves too intimately with others in order to avoid the burdensome social investments demanded in certain social exchanges (King, 1991). Moreover, in contrast to people in low context cultures, Chinese are inclined to approach this kind of relationship regulation in a subtle and implicit manner in order not to disturb the surface interpersonal harmony (Chang, 2001). 
Given its flexibility, mobile communication provides a trouble-free means for people to proactively avoid communication or delay it to a proper time and context by allowing people to hide their physical location and manipulate situational contexts.

Ms. Wang: ... a former classmate of mine called me a few days before my wedding. I didn't answer him because if I had I'd have been obligated to tell him about the wedding. I didn't want him to come.

Interviewer: But what if he asks you about the call and the wedding next time you see him?

Ms. Wang: I just told him that I didn't get his call... The signals were bad at the moment or the missed call message failed to show up... It happens...

Interviewer: So you did see him later.

Ms. Wang: Yeah, of course. I had dinner with him and other classmates later. I brought them candies from my wedding [it is a Chinese tradition to share candies from the wedding with people] and apologized for not inviting them to my rather simple wedding, so on and so forth. So, he didn't mind. He was fine.

In addition, the caller identification function allows people to screen callers and adopt the appropriate role for the incoming caller:

Ms. ZZ: Caller ID allows me to be proactive in dealing with people... I'd know who's calling and guess what the person is calling about. So I can choose if I will answer it or if it is a good time to talk with the person. 
Interviewer: If you choose not to answer the person, what do you do when the caller asks you about it later?

Ms. ZZ: There are plenty of excuses: I was on a business trip in Guangzhou. I just lost my phone and I wasn't able to recover the number... Or more often, the caller would "get it" after several missed calls and change course...

Screening phone calls is certainly not unique to Chinese users. People in other cultures may do it to restore their right to privacy or free themselves from unexpected or impropriate disturbances (Geser, 2004). However, relationship avoidance in Chinese mobile communication is practiced by interlocutors in specific encounters and in accordance with their specific identities. These practices confer meaning to and centralize social harmony in Chinese cultural life (Chang, 2001).

Indeed, the ability to achieve a harmonious relationship becomes the main criterion for evaluating whether an individual is competent in the process of Chinese communication (Chen, 2008). It is interesting to note that in the interviews, informants were not hesitant nor did they show much guilt in admitting that they often resorted to "white mobile phone lies" to escape unwanted communication. In fact, relationship avoidance in mobile communication is more like a test for social competence of both parties than an occasion for moral judgment of the recipient.

While relationship norms affect the use of communication technology, the latter also provides new resources to negotiate social exchanges. Many interviewees gave examples of how they manage encounters and establish or diminish feelings of 
connection by regulating their availability and the rhythm of the communication (Kim et al, 2007; Nardi, 2005).

Mr. Yuan: I try not to call her [the person in charge of the admissions office] too often. It would be annoying to her. I would come off as being too eager. I'm a qualified candidate after all...

Ms. Pang: I usually call him [her boyfriend] more than he calls me. But he would call when I get off work late or when it rains or something... to check if I'm all right. I guess we do care for each other equally...

Ms. Hong: I have this client. Very very annoying. He calls often. When I answer, I have to chat with him, this and that... So I set up a voicemail service for people like him. And I never return his calls immediately...He likes me? I don't care. I wish I could just tell him to leave me alone...

These cases demonstrate that mobile communication makes it possible to adjust and negotiate roles, hierarchies and forms of power in social relationships. In this sense, the mobile phone may help turn established roles or expected norms to mutual reachability (Licoppe \& Smoreda, 2005).

\section{Discussion}

Enabling a personal style of sociality, the mobile phone reifies the consistent tension 
between the competing needs for autonomy and sociability. Consequently, it invokes concerns about defining appropriate boundaries between public and private in Western societies (Katz \& Aakhus, 2002; Livingstone, 2005). The purpose of this study is to chart more closely culturally shaped, socially constituted, and contextually relevant mobile communication in Chinese society in an effort to extend such discussions beyond the West.

The great divide between private and public prescribes the mobile phone's normative expectations as mainly a personal and private apparatus in individualistic cultures. Research emphasizes that people in those cultures use the mobile phone primarily to keep in close touch with a relatively small and tightly knit circle of family and friends (Ling, 2004; Wajcman, et al., 2008). This has led to concerns about social cohesion in the broader social world (Geser, 2006; Ling, 2008). In contrast, Chinese mobile users maintain a large and open network of mobile contacts. These social connections not only include family and close friends but also work relations and peripheral social ties. Pervasive mobile communication flows freely on a web of mixed social ties that is both personal and instrumental, private and public. In a sense, the trope of the mobile phone for Chinese users is less an extension of private self than a mobile interface to their social universe.

Similarly, the private / public dynamic also frames our understandings of temporal and spatial mobility enabled by mobile telephony. While concerned about the mobile phone's capacity to blur the boundaries between work and personal time, private and public spaces, and consequently private and public life, mainstream discourse celebrates its power to free people from temporal-spatial restrictions and grant people the 
spirit of perpetual contact in the private sphere. This study provides preliminary evidence that the mobile phone helps Chinese users regulate social distance with their complex social relations across the two spheres. They use it to define and negotiate in-group membership, maintain social cohesion through mediated rituals, observe relational hierarchies and perform social harmony through mobile etiquettes and strategies. In fact, mobile etiquette, defined along spatial, temporal and more important contextual dimensions, becomes part of the social interaction that defines a relationship. To the extent that the mobile phone plays into the particularistic, indirect, and high-context patterns of social interaction guided by relation-oriented Chinese cultural norms, "perpetual contact" gives way to contextualized mobility.

Culture conditions our thinking and behavior. It manifests through communication patterns that are increasingly mediated by technologies. The uses and implications of the mobile phone need to be understood within the social context in which they are used. However, we should not take a simplistic and deterministic perspective in our approach. In fact, culture itself is a complex historical variable. Existing research suggests that while some core and deep-rooted Confucian values, such as interpersonal harmony and guanxi social networks, are resilient and may coexist with modernity, some traditional Chinese cultural values are already being transformed in response to the rapid process of modernization and globalization in Chinese society (Gold, et al., 2002; Hwang, 1987). Moreover, while cultural values and norms may help explain some variances of mobile communication, other factors such as the distinctiveness of the Chinese mobile phone market, local regulations, as well as 
individual variations in social relationship and communication patterns cannot be excluded from the complete picture. 


\section{References}

Benkler, Y. (2006). The wealth of networks: How social production transforms markets and freedom. New Haven, CT: Yale University Press.

Boase, J. (2008). Personal networks and the personal communication system: Using multiple media to connect. Information, Communication \& Society, 11(4), 490508

Campbell, S.W. (2008a). Mobile technology and the body: Apparatgeist, fashion, and function. In J. Katz, (Ed.), Mainstreaming mobiles: Wireless communication and social change in a global context (pp. 153-164). Cambridge, MA: MIT Press.

Campbell, S.W. (2008b). Perceptions of mobile phone use in public: The roles of individualism, collectivism, and focus of the setting. Communication Reports, 21(2), 70-81.

Campbell, S.W., \& Park, Y.J. (2008). Social implications of mobile telephony: The rise of personal communication society. Sociology Compass, 2(2), 371-387.

Castells, M., Fernandez-Ardevol, M., Qiu, J.L., \& Sey, A. (2007). Mobile communication and society: A global perspective. Cambridge, MA: MIT Press.

Chang, H. (2001). Harmony as performance: The turbulence under Chinese interpersonal communication. Discourse Studies, 3(2), 155-179.

Chen, G. (2008). Towards transcultural understanding: A harmony theory of Chinese communication. China Media Research, 4(4), 1-13.

Chinese Cultural Connection (1987). Chinese values and the search for culture-free dimensions of culture. Journal of Cross-Cultural Psychology, 18(2), 143-164. 
Chinese Ministry of Information Industry. (2010). 2010 Statistics of Telecommunications Industry. Retrieved from Chinese Ministry of Information Industry website: http://www.miit.gov.cn/n11293472/n11293832/n11294132/n12858447/13011909. $\underline{h t m l}$

Choi, J.H. (2007). Approaching the mobile culture of East Asia. M/C: A Journal of Media and Culture, 10(1). Retrieved from http://journal.mediaculture.org.au/0703/01-choi.php.

de Gournay, C. (2002). Pretense of intimacy in France. In J.E. Katz \& M.A. Aakhus (Eds.), Perpetual contact: Mobile communication, private talk, public performance (pp. 193-205). Cambridge, MA: Cambridge University Press.

Fairfield, P. (2005). Public/Private. Lanham, MD: Rowman \& Littlefield Publishers, Inc. Fortunati, L. (2002). Italy: Stereotypes, true and false. In J.E. Katz \& M.A. Aakhus (Eds.), Perpetual contact: Mobile communication, private talk, public performance (pp. 42-62). Cambridge, MA: Cambridge University Press.

Fortunati, L., Manganelli, A. M., Law, P., \& Yang, S. (2008). Beijing calling... Mobile communication in contemporary China. Knowledge, Technology \& Policy, 2, 1927.

Gant, D., \& Kiesler, S. (2001). Blurring the boundaries: Cell phones, mobility, and the line between work and personal life. In B. Brown, N. Green, \& R. Harper (Eds.), Wireless world: Social and interactional aspects of the mobile age (pp. 121-131). London, UK: Springer-Verlag.

Garcelon, M. (1997). The shadow of the Leviathan: Public and private in communist and post-communist society. In J. Weintraub \& K. Kumar (Eds.), Public and private 
in thought and practice (pp. 303-332). Chicago: University of Chicago Press.

Geser, H. (2004). Towards a sociological theory of the mobile phone release 3.0. Retrieved from http://socio.ch/mobile/t_geser1.htm

Geser, H. (2006). Is the cell phone undermining the social order?: Understanding mobile technology from a sociological perspective. Knowledge, Technology, \& Policy, 19(1), 8-18.

Gold, T., Guthrie, D., \& Wank, D. (Eds.). (2002). Social connections in China:

Institutions, culture, and the changing nature of guanxi. Cambridge, UK: Cambridge University Press.

Goodwin, R. (1999). Personal relationships across cultures. New York: Routledge.

Hall, E.T. (1976). Beyond culture. Garden City, NY: Anchor Press.

Hwang, K.K. (1987). Face and favor: The Chinese power game. American Journal of Sociology, 92(4), 944-974.

Ishii, K. (2006). Implications of mobility: The uses of personal communication media in everyday life. Journal of Communication, 56(2), 346-365.

Jones, S.G. (Ed.). (1998). CyberSociety 2.0: Revisiting computer-mediated communication and community. New York: Sage

Kakihara, M., \& Sorensen, C. (2002). Mobility: An extended perspective. Proceedings of the $35^{\text {th }}$ Hawaii International Conference on System Sciences. IEEE Computer Society Press, 1756-1766. Retrieved from http://ieeexplore.ieee.org/xpl/freeabs_all.jsp?arnumber=994088

Katz, J. (Ed.). (2008). Handbook of mobile communication studies. Cambridge, MA: The MIT Press. 
Katz, J.E., \& Aakhus, M.A. (Eds.). (2002). Perpetual contact: Mobile communication, private talk, public performance. Cambridge, UK: Cambridge University Press.

Kim, H., Kim, G.J., Park, H.W., \& Rice, R.E. (2007). Configurations of relationships in different media: FtF, email, instant messenger, mobile phone, and SMS. Journal of Computer-Mediated Communication, 12(4), 1183-1207.

Kim, S.D. (2002). Korea: Personal meanings. In J.E. Katz \& M.A. Aakhus (Eds.), Perpetual contact: Mobile communication, private talk, public performance (pp. 63-79). Cambridge, MA: Cambridge University Press.

King, A.Y. (1991). Kuan-hsi and network building: A sociological interpretation. Daedalus, 120(2), 63-84.

Kipnis, A.B. (2002). Practices of guanxi: Production and practices of ganqing avoidance. In T. Gold, D. Guthrie, \& D. Wank (Eds.), Social connections in China: Institutions, culture, and the changing nature of guanxi (pp. 21-34). Cambridge, UK: Cambridge University Press.

Law, P., \& Peng, Y. (2008). Mobile networks: Migrant workers in southern China. In J. Katz (Ed.), Handbook of mobile communication studies (pp. 55-64). Cambridge, MA: The MIT Press.

Licoppe, C. \& Smoreda, Z. (2005). Are social networks technologically embedded?: How networks are changing today with changes in communication technology. Social Networks, 27(4), 317-335.

Lincoln, Y.S. \& Guba, E.G. (1985). Naturalistic inquiry. Newbury Park, CA: Sage.

Ling, R. (2004). The mobile connection: The cell phone's impact on society. San Francisco, CA: Elsevier. 
Ling, R. (2008). New tech, new ties. Cambridge, MA: Cambridge University Press.

Ling, R., \& B. Yttri (2002). Hyper-coordination via mobile phones in Norway. In J.E. Katz \& M.A. Aakhus (Eds.), Perpetual contact: Mobile communication, private talk, public performance (pp.139-169). Cambridge, MA: Cambridge University Press.

Livingstone, S. (2005). Mediating the public/private boundary at home: Children's use of the Internet for privacy and participation. Journal of Media Practice, 6(1), 41-51.

Nardi, B.A. (2005). Beyond bandwidth: Dimensions of connection in interpersonal communication. Computer Supported Cooperative Work, 14(2), 91-130.

Parsons, T. (1951). The social system. Glencoe, IL: The Free Press.

Pew Research Center. (2009). Teens and mobile phones over the past five years: Pew internet looks back. Retrieved from Pew Research Center website: http://www.pewinternet.org/Reports/2009/14--Teens-and-Mobile-PhonesData-Memo.aspx

Qiu, J.L. (2009). Working-class network society: Communication technology and the information have-less in urban china. Boston: The MIT Press.

Rheingold, H. (2002). Smart mobs: The next social revolution. Cambridge, MA: Perseus Books/Basic Books.

Shuter, R. (2011). Introduction: New Media Across Cultures—Prospect and Promise. Journal of International and Intercultural Communication, 4(4), 241-245.

Shuter, R., \& Chattopadhyay, S. (2010). Emerging interpersonal norms of text messaging in India and the United States. Journal of Intercultural Communication Research, 39(2), 123-147. 
Taylor, A. (2005). Introduction. In R.S. Ling \& P.E. Pedersen (Eds.), Mobile communications: Re-negotiation of the social sphere (pp. 85-91). Surrey, UK: Springer.

Wajcman, J., Bittman, M., \& Brown, E. J. (2008). Families without borders: Mobile phones, connectedness and work-home divisions. Sociology, 42, 635-652.

Wang, H., \& Wellman, B. (2010). Social connectivity in America: Changes in adult friendship network size from 2002 to 2007. American Behavioral Scientist, 53(8), $1148-1169$.

Wang, J. (2010, March 9). Chinese New Year breaks SMS records. Retrieved from http://www.mis-asia.com/opinion__and_blogs/bloggers/chinese-new-yearbreaks-sms-records

Wei, R., \& Lo, V.H. (2006). Staying connected while on the move. New Media \& Society, 8(1), 53-72.

Weintraub, J. (1997). The theory and politics of the public/private distinction. In J.Weintraub \& K. Kumar (Eds.), Public and private in thought and practice (pp. 1-42). Chicago: University of Chicago Press.

Wellman, B. (2001). Physical place and cyberplace: The rise of personalized networking. International Journal of Urban and Regional Research, 25(2), 227-252.

Yan, Y. (2010). The individualization of Chinese society. Oxford, UK: Berg Publishers.

Yum, J.O. (1988). The impact of Confucianism on interpersonal relationships and communication patterns in East Asia. Communications Monographs, 55(4), 374388. 
Zhu, Y., Nel. P., \& Bhat, R. (2006). A cross-cultural study of communication strategies for building business relationships. International Journal of Cross Cultural Management, 6(3), 319-341. 